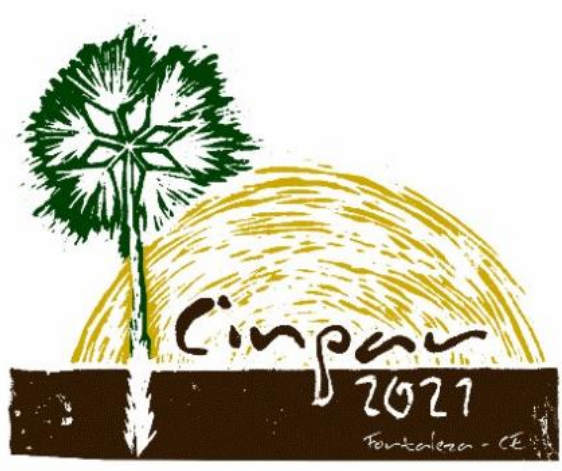

XVII Congresso Internacional sobre Patologia e

Reabilitação das Construções

XVII Congreso Internacional sobre Patología y Rehabilitación de las Construcciones

XVII International Conference on Pathology and Constructions Rehabilitation

FORTALEZA (Brasil), 3 a 5 de junho de 2021

https://doi.org/10.4322/CINPAR.2021.138

\title{
Aplicação da Norma ABNT NBR 16747 (2020) - Inspeção Predial em Empreendimentos Rurais - Estudo de Caso
}

\section{Application of ABNT Standard NBR 16747 (2020) - Building Inspection in Rural Enterprises - Case Study} \author{
MARTINI ${ }^{4}$ \\ ${ }^{1}$ CEFET/MG, Curvelo, Brasil, millacunha12@gmail.com \\ ${ }^{2}$ CEFET/MG, Curvelo, Brasil, marcos.ramos@cefetmg.br \\ ${ }^{3}$ CEFET-MG, Curvelo, Brasil, thiago.bortone@cefetmg.br \\ ${ }^{4}$ CEFET-MG, Curvelo, Brasil, martini@cefetmg.br
}

Camilla Cristina Cunha MENEZES ${ }^{1}$, Marcos de Paulo RAMOS², Thiago Pena BORTONE ${ }^{3}$, Rachel Jardim

\begin{abstract}
Resumo: Os empreendimentos rurais surgem frente à capacidade de solucionar problemas e criar oportunidades ligadas ao setor rural, em produtos benéficos para a sociedade em geral. Em relação às edificações que abrangem estes empreendimentos, torna-se notória a necessidade do emprego de novas técnicas construtivas. Tais técnicas visam a melhoria contínua do sistema construtivo, eficácia da funcionalidade e a minoração da deterioração precoce dos sistemas constituintes, de forma a suprir as necessidades produtivas, assegurando a integridade física dos usuários e da comunidade em seu entorno. A Inspeção Predial, procedimento sensorial, corresponde a avaliação/análise das condições técnicas, de uso, operação, manutenção, funcionalidade e desempenho de uma edificação. As diretrizes relativas a essa atividade encontram-se prescritas na norma ABNT NBR 16747:2020, devendo ser executadas por profissionais habilitados. O trabalho em questão objetiva a Inspeção Predial em uma edificação de empreendimento rural, aplicando-se as especificações normativas vigentes, e se inicia com solicitação e análise dos documentos da edificação (etapa A e B) e da anamnese (etapa C), entrevistas para identificar as características construtivas, como idade, histórico de manutenção, intervenções, reformas e alterações de uso ocorridas. Na etapa $D$ de vistoria foram identificadas as irregularidades e as manifestações patológicas existentes. Posteriormente as irregularidades foram classificadas (etapa E) e as recomendações das ações necessárias para a restauração ou preservação do desempenho do sistema construtivo da edificação afetado pelas anomalias foram apresentadas (etapa F), considerando o nível de prioridade das intervenções (etapa G). A edificação estudada foi projetada para um empreendimento na zona rural, construída com paredes de alvenaria tradicional de blocos cerâmicos e a estrutura de concreto armado. As etapas metodológicas propostas pela ABNT NBR 16747:2020 orientaram o trabalho de inspeção do empreendimento rural, simplificando o processo de apresentação das recomendações necessárias para restaurar e/ou preservar o desempenho dos sistemas e elementos construtivos da edificação.
\end{abstract}

Palavras-chave: Empreendimentos rurais, patologias, inspeção predial.

Abstract: Rural enterprises appear in the face of the ability to solve problems and create opportunities linked to the rural sector, in products that are beneficial to society in general. In relation to buildings that comprise these developments, the need for the use of new construction techniques becomes evident. Such techniques aim at the continuous improvement of the construction system, effectiveness of the functionality and the reduction of the precocious deterioration of the constituent systems, in order to supply the productive needs, ensuring the physical integrity of the users and the community in their surroundings. Building inspection, a 
sensory procedure, corresponds to the evaluation / analysis of technical conditions, use, operation, maintenance, functionality and performance of a building. The guidelines related to this activity are prescribed in ABNT NBR 16747:202), and must be carried out by qualified professionals. This paper aims at building inspection in a rural enterprise building, applying the current normative specifications, and begins with the request and analysis of the building documents (step $A$ and $B$ ) and the anamnesis (step C), interviews for identify the constructive characteristics, such as age, maintenance history, interventions, reforms and changes in use that have occurred. In stage $D$ of inspection, irregularities and existing pathological manifestations were identified. Subsequently, the irregularities were classified (step E) and the recommendations of the necessary actions for the restoration or preservation of the performance of the building's construction system affected by the anomalies were presented (step F), considering the priority level of the interventions (step $\mathrm{G}$ ). The studied building was designed for an enterprise in the rural area, built with traditional masonry walls of ceramic blocks and the reinforced concrete structure. The methodological steps proposed by ABNT NBR 16747:2020 guided the inspection work of the rural enterprise, simplifying the process of presenting the necessary recommendations to restore and / or preserve the performance of the building's building systems and elements.

Keywords: Rural enterprises, pathologies, building inspection.

\section{Introdução}

Conforme Garrido (2006), as organizações orientadas à exploração extrativa, agrícola ou agroindustrial para fins de beneficiamento social são denominados empreendimentos rurais. Segundo Camargo et al. (2001), grande parte dos projetos de edificações rurais exibem particularidades distintas de acordo com as exigências necessárias para cada atividade desenvolvida, observando os parâmetros de conforto e segurança.

De acordo com Sampaio (2014), no Brasil, constata-se que a deterioração de edificações rurais se tornou comum nos últimos anos, devido a constantes eventos climáticos de grande ou moderada intensidade. As manifestações patológicas, conforme descrito pela NBR 16747, ocorrem em decorrência de um processo de degradação de materiais, componentes e sistemas constituintes, apresentando sinais e sintomas com redução do desempenho das edificações (ABNT, 2020). Neste âmbito, é de suma importância a propagação de informações técnicas que possa reverter ou minimizar possíveis perdas de desempenho das edificações.

Sampaio (2014) relata que "[...] devido às condições de extremos climáticos cada vez mais repetitivos, os erros e as patologias existentes nas estruturas podem favorecer o colapso das edificações rurais, seja na sua totalidade ou em alguns pontos de enfraquecimento das estruturas".

Guimarães (2018) enfatiza que as manifestações patológicas do tipo fissuras e trincas podem ser ocasionadas por vários fatores como a dilatação térmica, ocorrência de sobrecargas, movimentação higroscópica, deformação excedente de elementos estruturais ou recalques diferenciais. Estas anomalias são recorrentes em edificações rurais onde se verifica que a maioria das construções são realizadas com quase nenhum aporte técnico.

De acordo com o Instituto Brasileiro de Avaliações e Perícias de Engenharia - IBAPE, a Inspeção Predial tem por finalidade "[...] a avaliação das condições técnicas, de uso, operação, manutenção e funcionalidade de uma edificação" (IBAPE, 2021). Para a realização da Inspeção Predial o profissional habilitado deve estar inteirado das regras e normas vigentes.

\subsection{Inspeção em Edificações}

De acordo com a IBAPE (2012), há formas de se evitar o colapso e deterioração precoce das edificações. A implementação de avaliações periódicas do uso e desempenho das edificações garantem posteriormente manutenções técnicas orientadas a restauração dos elementos comprometidos do imóvel. No contexto da Engenharia Civil a manutenção é delineada como "[...] conjunto de atividades e recursos que garanta o melhor desempenho da edificação para atender as necessidades dos usuários, com confiabilidade e disponibilidade, ao menor custo possível" (IBAPE/PR, 2016).

$\mathrm{O}$ procedimento empregado na vistoria deve abranger os critérios de segurança, habitabilidade e sustentabilidade. A metodologia de Inspeção Predial, conforme NBR 16747 (ABNT, 2020) é composta pelas 
seguintes etapas: A) levantamento de dados e documentação; B) verificação dos dados e documentação disponibilizada; C) anamnese; D) vistoria sensorial do imóvel e das instalações; E) análise e classificação das anomalias levantadas; F) instrução quanto às ações de reparação, G) organização das ações de manutenção e reparo em patamares de urgência, considerando o nível de prioridade das intervenções; $H$ ) avaliação da manutenção; I) avaliação de uso da edificação; J) elaboração e emissão do laudo técnico.

$\mathrm{Na}$ Construção Civil a anamnese trata-se de uma entrevista com o proprietário e usuários do local, onde se busca o entendimento dos sistemas constituintes da edificação, auxiliando no diagnóstico assertivo das manifestações patológicas e melhorando a orientação quanto às ações preventivas e corretivas. Fundamentado de acordo a norma NBR 16747 (ABNT, 2020), o laudo técnico de vistoria elaborado a partir da Inspeção Predial torna-se uma ferramenta relevante no levantamento de anomalias, falhas construtivas e manifestações patológicas que afetam a funcionalidade da edificação bem como a segurança dos usuários. Com o laudo técnico pretende-se que as decisões de intervenção sejam objetivas e baseadas em documentos de fácil interpretação e utilização, embora essencialmente de base técnica (LANZINHA, 2002).

\section{Metodologia de Estudo}

A Inspeção Predial foi executada de acordo com os requisitos normativos da NBR 16747 (ABNT, 2020). 0 método de avaliação sensorial utilizado consiste na observação das partes constituintes da edificação buscando evocar e interpretar o estado de conservação e as manifestações características presentes. De modo a obter informações prévias de falhas construtivas, modificações e histórico da construção, foi realizada a entrevista preliminar com os colaboradores do empreendimento. Foi realizada posteriormente a análise das documentações administrativas objetivando identificar se o imóvel estava de acordo com as atribuições técnicas e legais, considerando a tipologia do empreendimento estudado.

\subsection{Estudo de caso}

Neste trabalho o enfoque são as unidades de produção rural conhecidas como empreendimentos rurais. 0 imóvel inspecionado está localizado na Região Central Mineira e pertence a uma empresa voltada a soluções tubulares empregadas nos setores industriais e civis de grande porte, equipamentos mecânicos de alto desempenho, poços de petróleo e usinas de geração de energia (Figura 1a e 1b). No empreendimento em questão são desenvolvidas as atividades relacionadas ao plantio e manejo de florestas de eucalipto para a produção de carvão vegetal, sendo notável no mercado nacional pelo desenvolvimento de tecnologias em pesquisas e mecanização das atividades.

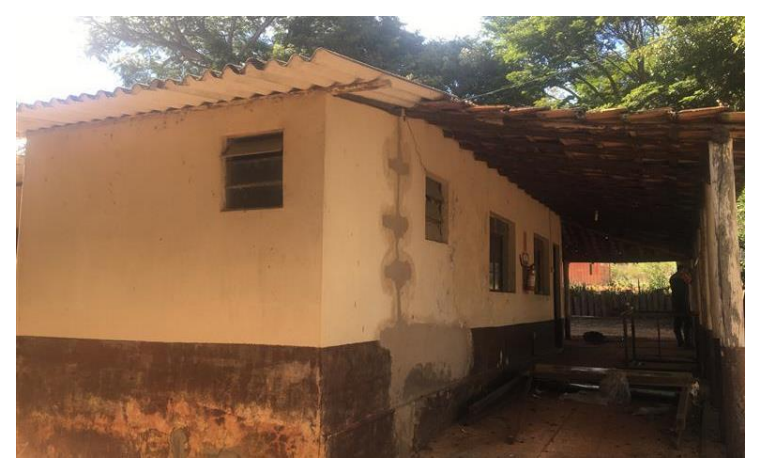

(a)

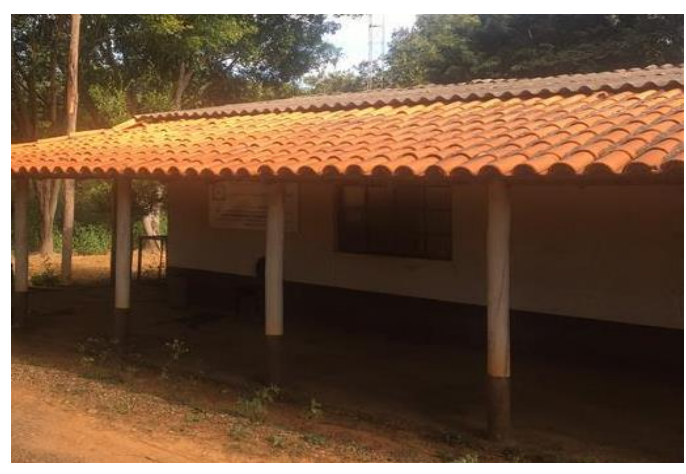

(b)

Figura 1 - Edificação Rural objeto de estudo

A justificativa do foco em edificações localizadas em ambientes rurais se dá pela exiguidade de pesquisas relacionadas à análise de dilemas patológicos frente a amplitude dos fatores exógenos naturais, eventos climáticos e meteorológicos que estas construções estão expostas. A análise das condições de conservação, manifestações patológicas e desempenho de construções com usos específicos, são essenciais para determinação de parâmetros de projeto, visando a mitigação de riscos e prolongamento da vida útil do sistema construtivo, podendo auxiliar na composição de planos de manutenções. 
Sertori (2012) declara que edificações rurais correspondem a um tema desprovido de reflexão, dispondo investimentos limitados para sua avaliação. Uma das causas de possível influência neste cenário esta relacionada às políticas públicas voltadas predominantemente para as unidades locadas na área urbana, possibilitando a realização de um número maior de pesquisas devido a localização acessível e maior disponibilidade de ferramentas de investigação se comparado à área rural.

Para a análise do empreendimento foi efetuada a inspeção de campo por intermédio de check-list, formulário destinado ao registro das constatações resultantes, que auxilia na verificação dos elementos inspecionados de acordo com os tópicos dispostos no Quadro 1.

Quadro 1 - Tópicos da inspeção de campo

\begin{tabular}{|c|c|}
\hline ITEM & TÓPICOS \\
\hline 1 & Estruturas \\
\hline 2 & Fundação \\
\hline 3 & Vedação \\
\hline 4 & Revestimento \\
\hline 5 & Esquadrias \\
\hline 6 & Impermeabilização \\
\hline 7 & Instalação hidrosanitária \\
\hline 8 & Instalação elétrica \\
\hline 9 & Cobertura \\
\hline 10 & Combate a Incêndio \\
\hline
\end{tabular}

Fonte: Carvalho et al. (2017).

Foram vistoriados os elementos da parte externa e interna do imóvel, a começar pela área externa onde foram verificados itens como a estação de tratamento de água, dutos de escoamento de água pluvial, paredes externas, cobertura, pilares de madeira e a presença de anomalias na estrutura. Na parte interna do imóvel foram verificados: forro de PVC, paredes de vedação, elementos estruturais, esquadrias e o piso cerâmico.

Os sistemas hidráulicos foram inspecionados no sentido descendente abrangendo os elementos visíveis, observando as anomalias que indicassem perdas de desempenho ou demais manifestações em trechos não aparentes, como infiltrações evidentes. Para inspecionar os sistemas elétricos, foi verificado o medidor de entrada da fazenda até as suas ramificações de distribuição interna, inspecionados todos os quadros elétricos, fiações aparentes e dispositivos de segurança instalados.

O registro fotográfico realizado evidenciou o estado de conservação dos elementos, anomalias aparentes e outros aspectos relevantes levantados, para posterior classificação apresentada no Quadro 2. Esta classificação está de acordo com o risco ofertado aos usuários das edificações, ao meio ambiente e impacto causado à vida útil da edificação.

Quadro 2 - Critérios de organização das prioridades em patamares de urgência

\begin{tabular}{|c|c|}
\hline Prioridade & Gravidade \\
\hline 1 & $\begin{array}{c}\text { Perda de desempenho compromete a saúde e/ou seguranças dos } \\
\text { usuários, do meio ambiente ou do próprio edifício }\end{array}$ \\
\hline 2 & $\begin{array}{c}\text { Perda parcial de desempenho que impacta a funcionalidade da } \\
\text { edificação, sem prejuízo à operação, sem comprometer a saúde } \\
\text { e/ou seguranças dos usuários }\end{array}$ \\
\hline 3 & Perda de desempenho pode ocasionar pequenos prejuízos à estética \\
\hline
\end{tabular}

Aplicação da Norma ABNT NBR 16747 - Inspeção Predial em Empreendimentos Rurais - Estudo de Caso 
Segundo a NBR 5674 (ABNT, 2012), a fim de garantir o máximo desempenho no controle de uma edificação ou agrupamento delas, torna-se fundamental o desenvolvimento de planos de manutenção embasados no planejamento de gestão de custos, melhores condições de preservação e maior satisfação do cliente (ABNT, 2012).

\section{Resultados e Discussões}

Durante a inspeção predial foram observadas algumas manifestações patológicas que serão apresentadas a seguir. Segundo Santos (2017), a identificação ágil das anomalias de uma edificação impedem seu agravamento colaborando para o aditamento da vida útil e sustentabilidade da estrutura.

Nas paredes de vedação da área externa foram detectadas fissuras e trincas inclinadas localizadas na parte superior e inferior das esquadrias (Figura 2 e 3). A ausência de vergas e contravergas, elementos estruturais incorporados na fase construtiva que suportam as cargas e tensões aplicadas, podem ter ocasionado estas anomalias.

De acordo com Thomaz (1986) em painéis de alvenaria em que se verificam aberturas, as trincas que surgem nos vértices destes vãos e sob o peitoril, podem ser atribuídas ao caminhamento das isostáticas de compressão.

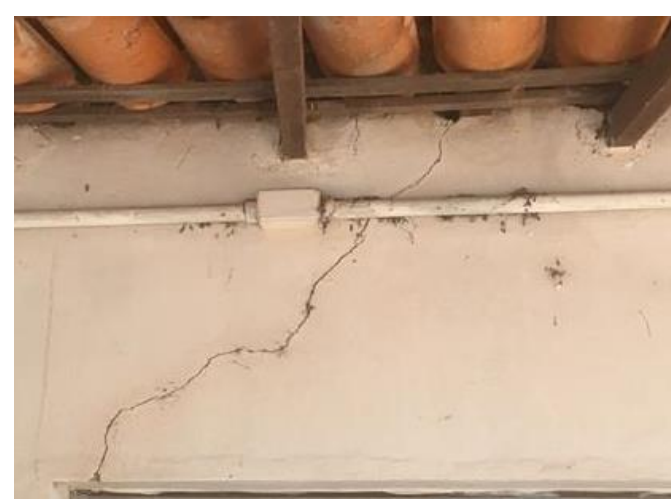

Figura 2 - Trincas e fissuras área externa

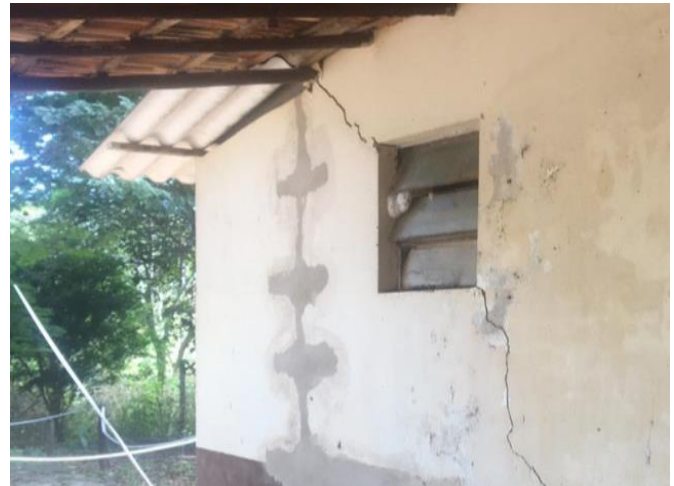

Figura 3 - Trinca e descascamento da pintura

Na figura 3 também é possível visualizar o descascamento da pintura, causado pela falta de aderência da tinta aplicada, que pode ter sido originada pela falta de preparação do substrato, diluição inadequada do material ou aplicação de materiais de baixa qualidade.

Sobre a cobertura do banheiro masculino localiza-se uma caixa d'água, o peso deste elemento juntamente com o peso próprio da estrutura pode ter ocasionado uma sobrecarga na parede de vedação originando a trinca observada na figura 4.

$\mathrm{Na}$ área externa observou-se que alguns pilares de madeira de sustentação da cobertura apresentavam desgaste na extremidade inferior (Figura 5). Segundo Kropf (2000) "[...] a durabilidade da madeira passou a ser alcançada através de preservação química de toda seção transversal". Sobre o fator de preservação, o apodrecimento e ataque de insetos danosos comprometem o desempenho estrutural da peça.

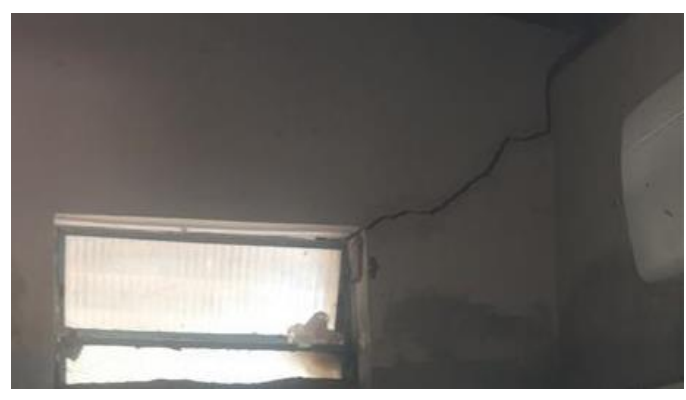

Figura 4 - Fissuras banheiro masculino

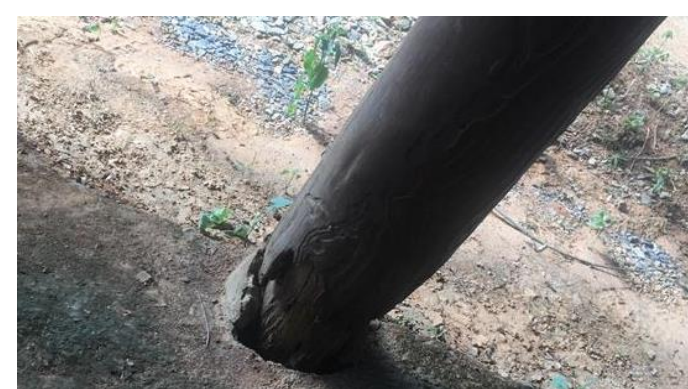

Figura 5 - Desgaste no pilar de sustentação da cobertura 
No interior da edificação foram encontradas nas paredes manchas de infiltrações, conforme apresentado na figura 6 , provenientes do vazamento de água da cobertura que possuía algumas telhas quebradas e deslocadas.

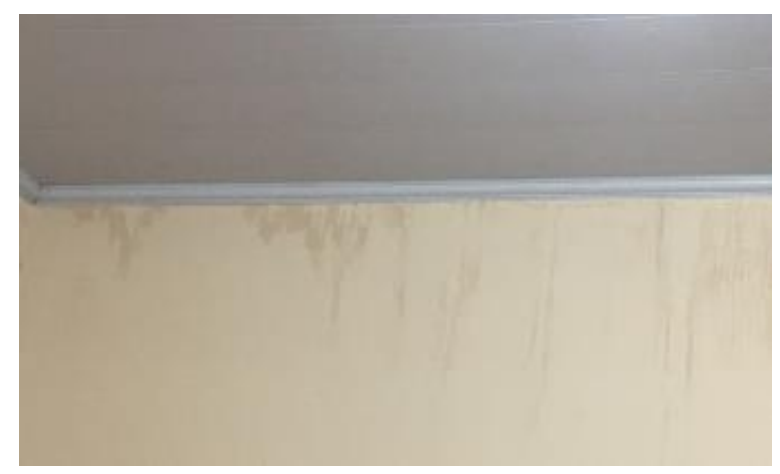

Figura 6 - Infiltração parede interna da cozinha

\subsection{Recomendações técnicas e organização das prioridades}

As orientações apresentadas a seguir foram embasadas em bibliografias, importante salientar que o plano de manutenção deve ser projetado e acompanhado por profissionais habilitados.

\subsubsection{Pilar de madeira deteriorado}

Na situação observada na figura 5, recomenda-se a substituição do pilar de madeira, por outra peça do material previamente tratada, mantendo o padrão estético dos demais pilares de suporte da cobertura. Conforme Cardoso (2010) o escoramento deve ser realizado a fim de garantir a segurança da estrutura no decorrer da execução. Para encaixe do pilar a estrutura de cobertura deve ser realizada a ligação por parafusos ou por entalhe. A ligação pilar-fundação pode ser feita empregando-se conectores metálicos (GANDINI, 20016).

\subsubsection{Fissuras e trincas}

O objetivo do tratamento das fissuras é inibir a entrada de umidade e gases prejudiciais à estrutura. Deve ser averiguado se as trincas observadas nas figuras 2, 3 e 4 estão estabilizadas ou ativas e seguir com o procedimento de recuperação conforme descrito por Sahade (2005). Primeiramente realizar a preparação da superfície abrindo-se com a ajuda de uma talhadeira um sulco sobre o revestimento com $12 \mathrm{~cm}$ de largura por 3 a $4 \mathrm{~mm}$ de profundidade, remove-se o material do revestimento, realizando também a limpeza do sulco formado com o auxílio de um pincel. Para o tratamento da pintura realiza-se a calefação do substrato com a massa acrílica e após 24 horas de secagem aplica-se a tela de poliéster com bandagem central de polipropileno nas dimensões de $100 \mathrm{~mm} \times 30 \mathrm{~mm}$. Aplica-se em seguida uma segunda demão de massa acrílica sobre a tela, preenchendo todo sulco. Para o acabamento final após aguardar a secagem do produto por 24 horas, realiza-se o lixamento e pintura com duas demãos de tinta látex acrílica (SAHADE, 2005).

\subsubsection{Manchas de infiltrações}

Primeiramente deve ser realizada a manutenção da cobertura, fazendo a substituição das telhas danificadas para inibir a percolação de água pelas paredes. Para o reparo das manchas identificadas na figura 6 , causadas pela infiltração por capilaridade Santos (2020) recomenda a aplicação da solução de água com água sanitária, na dosagem de 1:1, com hidro jateamento no tijolo aparente. Após a limpeza completa aplicar uma camada de impermeabilizante. Aguardar a secagem do produto, em torno de 24 horas, para aplicação da tinta como acabamento. 


\subsubsection{Descascamento da pintura}

Campos (2009) orienta que para correção de anomalias como a verificada na figura 3 , deve-se remover através de jateamento ou raspagem das partes sem aderência. Em seguida aplicar uma demão de fundo preparador de paredes para posterior acabamento com a tinta acrílica para exteriores.

De acordo com os riscos apresentados e conforme recomendações apresentadas, as recomendações técnicas foram organizadas em patamares de urgência buscando restaurar os elementos construtivos comprometidos pelas anomalias identificadas, conforme apresentado no Quadro 3. Em uma ação de restauração não se objetiva a alteração ou modificação das características iniciais do elemento, mantendo a integridade do bem imóvel, observando cada elemento e sua função frente o desempenho da edificação.

Quadro 3 - Organização das prioridades

\begin{tabular}{|c|c|}
\hline Prioridade & Manifestação patológica \\
\hline Prioridade 1 & Pilar de madeira deteriorado \\
\hline Prioridade 2 & Trincas e rachaduras \\
\hline Prioridade 2 & Manchas de infiltrações \\
\hline Prioridade 3 & Descascamento da pintura \\
\hline
\end{tabular}

\section{Conclusões}

Através do processo de Inspeção Predial orientado pela NBR 16747 (ABNT, 2020), foram identificadas as principais manifestações patológicas que comprometiam o desempenho eficaz da edificação. A inspeção também contribui para um bom plano de manutenção que atua diretamente na gestão eficaz do empreendimento. As falhas averiguadas possivelmente podem ter sido originadas devido a falhas na concepção do projeto, processo construtivo ou desvios das manutenções periódicas.

As manifestações patológicas identificadas foram fissuras, trincas e rachaduras nas paredes de vedação, manchas de umidade devido a avarias no sistema de cobertura, deterioração de peças estruturais de madeira e descamação da camada de pintura das paredes externas que sofrem diariamente com a ação do sol, chuva e outros agentes patológicos.

Para estudos futuros pretende-se ampliar a amostragem de inspeções, abrangendo outros tipos de empreendimento rurais, buscando auxiliar na mitigação e deterioração precoce das edificações, além de assessorar na difusão de informações que auxiliem os proprietários e usuários quanto à preservação dos empreendimentos rurais e aumento da sua vida útil.

\section{Agradecimentos}

Agradecemos ao Centro Federal de Educação Tecnológica de Minas Gerais - CEFET-MG pelo apoio direto. Agradecemos também ao LAR - Laboratório de Avaliação e Reabilitação de Ambiente Construído CEFET-MG - Campus Curvelo, pelo apoio durante o desenvolvimento do estudo.

\section{Referências Bibliográficas}

Associação Brasileira De Normas Técnicas. NBR 16747: Inspeção Predial - Diretrizes, Conceitos, Terminologias e Procedimentos. Rio de Janeiro, 2020.

Camargo, M. L. R. M. Diretrizes gerais para o projeto estrutural de construções rurais. Dissertação (Mestrado em Engenharia Agrícola). Campinas - SP. Universidade Estadual de Campinas (Unicamp), 2001. 293p. 
Campos, R. F. S. Manutenção e reparo de fachadas de prédios comerciais no Rio Grande do Sul: procedimentos e custos envolvidos. Porto Alegre, 2009.

Carvalho, E. M., Almeida, L. S. CHECK-LIST PARA INSPEÇÕES PREDIAIS RESIDENCIAIS DE MÚLTIPLOS PAVIMENTOS: DESENVOLVIMENTO E APLICAÇÃO. Congresso Brasileiro de Engenharia de Avaliações e Perícias. Foz do Iguaçu: Paraná; 2017.

Dos Santos, A. L. M., De Lima, N. B.; Oliveira, R. A, Estolando, A. M. L., Berenguer, R. A., Lima, N. B. Análise De Métodos De Reparo Dos Danos Ocasionados Pela Infiltração Por Capilaridade Em Alvenarias.Congresso Brasileiro de Patologias das Construções. Fortaleza, 2020.

Ferreira, J. B; Lasso, Sarah Venturim; Mainardes, Emerson. Características empreendedoras do produtor rural capixaba. Gestão \& Regionalidade, v. 33, n. 99, 2017.

Gandini, J. M. D.; Barata, T.; Pablos, J. Sistemas construtivos em madeira certificada - Experiências desenvolvidas: Uma abordagem sobre projeto de interfaces e processo de racionalização de componentes. MIX Sustentável, v. 2, n. 1, p. 53-63, 2016.

Garrido, L. R., Sehnem, S. Gestão associativa no empreendimento rural. Revista de Administração, v. 5, n. 8, p. 65-88, 2006.

Guimarães, V. V. Souza, W. C. N., Silva, M. A. A. T., Ribeiro, I. J. C., Neto, J. L., Marinho, F. A. Influência da transposição do rio são francisco nas edificações rurais.

Instituto Brasileiro de Avaliações e Perícias de Engenharia do Paraná. Inspeção e Manutenção Predial. Disponível em: https://www.crea-pr.org.br/ws/wpcontent/uploads/2016/12/inspecao-e-manutencao predial.pdf. Acesso em: 04 jan 2020.

Kropf, F. W. Durabilidade e detalhes de projeto: o resultado de 15 anos de contínua implementação. Madeira: arquitetura e engenharia, v. 1, n. 1, 2014.

Lanzinha, J. C.; Castro Gomes, J. P.; Peixoto Feitas, V. Application of a building inspection method to a group of rural houses. In: XXX IAHS World Congress on Housing. 2002. p. 9-13.

Leitner, Camyla Piran Stiegler; Alves Filho, Alceu Gomes. Estratégia de operações: uma abordagem teórica quanto à aplicabilidade do constructo para empreendimentos rurais produtores de grãos. Gestão \& Produção, v. 26, n. 1, 2019.Campo Grande.

Lordsleem Jr., A.C. Sistemas de recuperação de fissuras da alvenaria de vedação: avaliação da capacidade de deformação. São Paulo, 1997. 174p. Dissertação (mestrado) - Escola Politécnica da Universidade de São Paulo.

Neves, Daniel Rodrigues Rezende; Branco, Luiz Antônio Mn. Estratégia de inspeção predial. Construindo, Belo Horizonte, v.1, n.2, p.12-19, jul./dez. 2009

Oliveira, D. F. Levantamento de causas de patologias na construção civil. Rio de Janeiro, 2013.

Sahade, R. F.. Avaliação de sistemas de recuperação de fissuras em alvenaria de vedação. São Paulo, SP: Dissertação para obtenção do grau de mestre em engenharia, Centro de Aperfeiçoamento Tecnológico do Instituto de Pesquisas Tecnológicas do Estado de São Paulo, 2005.

Sampaio, C. A. P., Terezo, R. F., Cardoso, C. O., Correggio, K. Colapsos De Edificações Rurais. Campo Grande 2014.

Santos, W. S.; Santos, A. L. C. Perfil dos empreendedores que atuam no turismo rural: um estudo de caso na microrregião de Feira de Santana (BA). Sitientibus, Feira de Santana, n. 39, p. 75-94, 2008.

Santos, R. G., Sousa, A. S., Guerra, E. P. M (2017). PATOLOGIAS EM EDIFICAÇÃO COM ESTRUTURA DE CONCRETO. Congresso Internacional sobre Patologia e Reabilitação de Estruturas - CINPAR 2017, Grato, Ceara; September 2017.

Sertori, R. J. V. O Mutirão do Projeto Inova rural: estratégias da assessoria técnica na produção da moradia rural. São Carlos, 2012. Dissertação (Mestrado em Arquitetura e Urbanismo) - Programa de PósGraduação em Arquitetura e Urbanismo, Universidade de São Paulo, São Carlos, 2012.

Thomaz, E. Trincas em edifícios: causas, prevenção e recuperação. Editora Pini. São Paulo, 1989, 189p.

Aplicação da Norma ABNT NBR 16747 - Inspeção Predial em Empreendimentos Rurais - Estudo de Caso 